\title{
1 Self-sensing concrete made from recycled carbon fibres
}

2

3 I. Segura ${ }^{\mathrm{a}, \mathrm{b}, *}$, G. Faneca ${ }^{\mathrm{d}}$, J. M. Torrents ${ }^{\mathrm{c}}$, A. Aguado $^{\mathrm{b}}$

4

${ }^{\text {a }}$ Smart Engineering Ltd., C/Jordi Girona 1-3, Parc UPC - K2M, 08034, Barcelona, Spain

${ }^{b}$ Department of Civil and Environmental Engineering, Universitat Politècnica de Catalunya -

7 Barcelona Tech, C1, 08034, Barcelona, Spain

$8 \quad{ }^{\mathrm{c}}$ Department of Electronics Engineering, Universitat Politècnica de Catalunya - Barcelona

9 Tech, C4, 08034, Barcelona, Spain

$10 \quad{ }^{\mathrm{d}}$ Escofet 1886 Ltd. 08760 Martorell Barcelona

\section{Abstract}

The electrical and piezo-resistive responses of recycled carbon fibre (rCF)-reinforced concrete is analysed in this article. Two different PAN-based rCFs (monofilament rCF and fibrillated rCF sheets) incorporated into dry concrete mix were investigated. Piezo-resistivity was evaluated by simultaneously monitoring the variation in the applied DC voltage during both

17 flexural and compressive tests. Although both plain and rCF-reinforced concrete samples showed piezo-resistive responses, the latter show increased signal-to-noise-ratio and thus behave like self-sensing materials. The electrical behaviour suggests a mixed control owing to both ionic and electronic conductivity, with the dominant one depending on the rCF content

* Corresponding author: Ignacio Segura Pérez. Universitat Politecnica de Catalunya. Departament d'Enginyeria de la Construcció. Carrer Jordi Girona 1-3, Edifico C1, despacho 202. E-08034 Barcelona. SPAIN. Email: ignacio.segura@upc.edu. Tel.: +34-93-401-65-30. Fax: +34-93-405-41-35 
and $\mathrm{rCF}$ dispersion. This work enhances the possibility of generalising the use of smart cementitious materials in the civil engineering industry.

\section{Keywords}

Self-sensing concrete; strain sensing; recycled carbon fibre; smart material

\section{INTRODUCTION}

Since the last 15 years, there is a revolution to turn civil infrastructures and buildings all over the world into smart structures. Our current society is increasingly demanding that the infrastructures and cities become smart and provide other functionalities in addition to their mechanical performance and durability. Furthermore, the recent failures in the summer of 2018 of a motorway bridge in Genova, Italy and of a concrete pier in Vigo, Spain, have brought the focus on how our society deals with infrastructure monitoring and maintenance. Moreover, there is a need to reduce monitoring costs and to avoid further collapse of existing infrastructures.

This revolution has mainly considered the incorporation of multi-functional devices and sensors into civil infrastructures and architectural heritage. Nowadays, optical fibres are widely employed for monitoring civil infrastructures [1], and wireless sensor networks (WSN) are being extensively used to help preserve the building heritage [2]. One of the main challenges of this approach is the durability of the sensors since they may become external agents in the structures. Experience reminds us of the lack of durability of such sensors, as evidenced by dam auscultation and WSN systems. The inconvenient truth is that almost $70 \%$ of the sensors fail or are inoperative after 1 year of operation [3]. To describe this situation in medical terminology, we are facing a serious problem of "transplant rejection" by our infrastructures. 
However, a very promising alternative to the use of conventional sensors is the development of smart cementitious materials with self-sensing abilities, which would allow detection of strain and damages in new and existing infrastructures. The incorporation of conductive phases into cementitious matrices has been one of the most popular methodologies to develop self-sensing cementitious materials. In 1993, Chen and Chung first reported the piezo-resistive effects of carbon fibre-reinforced cementitious materials [4]. The incorporation of conductive phases into the cementitious matrix modifies its conductive characteristic. Thus, piezo-resistive effect appears when stress is applied to the material, owing to the modification of the conductive characteristics of the material. For carbon fibre-reinforced composites, piezo-resistivity is considered to originate from the slight pull-out of crack-bridging fibres during crack opening and the consequent increase in the contact electrical resistivity of the fibre-matrix interface [5], or the conduction network degeneration resulting from fibre reorientation under finite strain $[6]$.

The piezo-resistivity of carbon fibre cementitious materials has been extensively investigated until now [7-12], and nowadays, it is being explored through the incorporation of graphene [13], carbon nanotubes (CNTs) and nanofibers [11,14-17], multiphasic mixes of conductive additives [18-21], and CNT-coated aggregates [22]. An interesting review on the development of self-sensing cementitious materials was published by Chan et al. [23]. However, the incorporation of smart materials into novel or existing infrastructures has not taken off, and has been limited to some pilot studies only $[8,17,24,25]$. One key reason for this situation is the high cost of the conductive phases that are being used in the development of smart cementitious materials. The use of recycled carbon fibres ( $\mathrm{rCF})$ is a very promising alternative in the development of sustainable smart cementitious materials. Recycled carbon fibres are mainly 
obtained from aerospace composite scrap. Among many different methods, most of the commercially available rCF are obtained via pyrolysis. This process allow a high retention (up to $90 \%$ ) of the properties exhibited by virgin carbon fibres $[26,27]$. The use of rCF may allow to design economically affordable smart cementitious materials since most of recycling processes yield rCF with high retention of mechanical properties [26] but with a 30 to 40 percent cost savings versus virgin carbon fibre (cost of commercial chopped carbon fibres: $15 € / \mathrm{kg}$ vs cost of $\mathrm{rCF}: 7-8 € / \mathrm{kg}$ ). In a recent paper [28], we demonstrated the possibility of using recycled carbon fibres to develop conductive cementitious materials, and realized electrical resistivities in the range of $3-0.6 \Omega \cdot \mathrm{m}$ for $\mathrm{rCF}$ contents ranging from 0.2 to $0.8 \%$ in vol.

As a continuation of this research, in this study, we explore the capability of recycled fibre cementitious composites as smart materials for self-sensing applications. Two different types of rCF (fibrillated and sheet-type) were evaluated as additives; these two were incorporated at different contents ( 0.1 to $1.4 \%$ in volume) in ultra-high-performance concrete (UHPC) mix. Piezo-resistivity of the prepared concrete samples was evaluated under both flexural and compressive conditions, by taking into account the effect of the moisture content of the samples.

\section{MATERIALS AND METHODS}

\subsection{Concrete dosage and raw materials}

The concrete dosage used in our study is shown in Table 1; this is characteristic of a UHPC dosage. This concrete dosage was selected because it is expected to enhance the electrical conductivity owing to the presence of a double percolation phenomenon, as described by Wen et al. [5]. The cement selected to produce the UHPC mixtures was a CEM I 53.5R. The sand used was siliceous sand and fine calcium carbonate powder (Betoflow) was incorporated into the different dosages to achieve an optimum workability of the mixes with a low consumption 
of superplasticisers. Both a polycarboxylate superplasticiser (Glenium ACE425) and nanosilica suspension (Meyco MS685) were used as additives to provide self-compacting characteristics to the concrete mix. The water to cement $(\mathrm{w} / \mathrm{c})$ ratio of the concrete mixes was 0.14 . Two different PAN-based rCF samples provided by ELG Carbon Fibre Ltd (C10/30, and CT12) were used in this study. The characteristics of the $\mathrm{rCF}$ are described in Table 2; C10/30 are monofilament $\mathrm{rCF}$ and $\mathrm{CT} 12$ are fibrillated sheets of $\mathrm{rCF}$. The fibre factor $F$ given by Eq. 1, as proposed by Narayanan and Darwish, allows to account for the effect of both the geometrical characteristics of the fibres, length $\left(L_{f}\right)$ and diameter $\left(d_{f}\right)$ [29].

where, $\beta$ is the fibre shape factor ( 0.50 for circular fibres), and the fibre was dosage varied from $0.1 \%$ to $1.4 \%$ in volume.

$$
F=\beta \cdot L_{f} / d_{f}
$$

$$
\text { (Eq. 1) }
$$


117 Table 2. Properties of recycled carbon fibres

\begin{tabular}{|c|c|c|}
\hline \multirow{2}{*}{ Property } & \multicolumn{2}{|c|}{ Value } \\
\cline { 2 - 3 } & $\mathbf{C 1 0} / 30$ & CT12 \\
\hline Diameter $(\mu \mathrm{m})$ & 7.5 & $7^{\dagger}$ \\
\hline Nominal length $(\mathrm{mm})$ & $10-30$ & 12 \\
\hline Average length $(\mathrm{mm})$ & 20 & 12 \\
\hline Fibre factor $F$ & 1428 & 12 \\
\hline Density $\left(\mathrm{kg} / \mathrm{m}^{3}\right)$ & 1800 & 1760 \\
\hline Tensile strength $(\mathrm{MPa})$ & 3150 & 4150 \\
\hline Young modulus $(\mathrm{GPa})$ & 200 & 252 \\
\hline Electrical resistivity $(\Omega \cdot \mathrm{m})$ & $0.103 / 0.34^{\dagger \dagger}$ & 0.016 \\
\hline
\end{tabular}

$\dagger$ The effective diameter of the fibrillated sheets is $500 \mu \mathrm{m}$.

${ }^{\dagger \dagger}$ The electrical resistivity value varies depending on whether the measurement is made lengthways (0.103) or along the cross-section (0.34)

\subsection{Sample fabrication}

123 UHPC samples with dimensions of $40 \times 40 \times 160 \mathrm{~mm}$ were fabricated with the dosages

124 indicated in Table 1, according to UNE-EN 196-1 [30]. The concrete samples were produced

125 at the industrial installations of the company, Escofet 1886, with a fabrication procedure

126 replicating the industrial process as closely as possible. Two sets of samples were fabricated

127 from each mix, one set for mechanical measurements and another for electrical

128 measurements. In this work, rCFs were added to the dry mix (D) after incorporating the

129 cement and aggregates. No specific dispersion procedure was implemented since our main

130 aim was to work as close as possible to the real practice and use the actual concrete

131 compositions used in the precast concrete industry. Reference samples were prepared without

132 adding rCF. The electrodes for the electrical measurements were stainless steel set screws of 5

$133 \mathrm{~cm}$ length that were introduced $3.5 \mathrm{~cm}$ deep into the concrete samples. The samples were

134 cured in a humid chamber $\left(20^{\circ} \pm 2{ }^{\circ} \mathrm{C}\right.$; relative humidity of $\left.95 \pm 5 \%\right)$ for 28 days. The

135 samples are designated according to the following code: U-Cf-f-M 
136 where, $\mathrm{U}$ stands for UHPC mixes, $\mathrm{C}_{\mathrm{f}}$ indicates the fibre content (which varies from 0 for the

137 reference sample to 14 for the $1.4 \%$ fibre content), $\mathrm{f}$ indicates the fibre type, and $\mathrm{M}$ indicates

138 the mixing method of the fibres (D).

139

\section{$140 \quad 2.3 \quad$ Characterisation}

141 Slump flow was measured according to UNE-EN 1015-3 [31] prior to the development of the

142 concrete samples. Flexural and compressive strength measurements were performed on the

143 concrete samples in compliance with UNE-EN 196-1 [30]; three and six replicates were made

144 for each dosage, respectively. The electrodes used for the electrical measurements were

145 stainless steel set screws of length $5 \mathrm{~cm}$, which were dipped $3.5 \mathrm{~cm}$ into the concrete samples.

146 The samples for mechanical strength measurements did not included steel electrodes. Figure 1

147 shows a scheme on the electrodes positioning on the specimens.

148

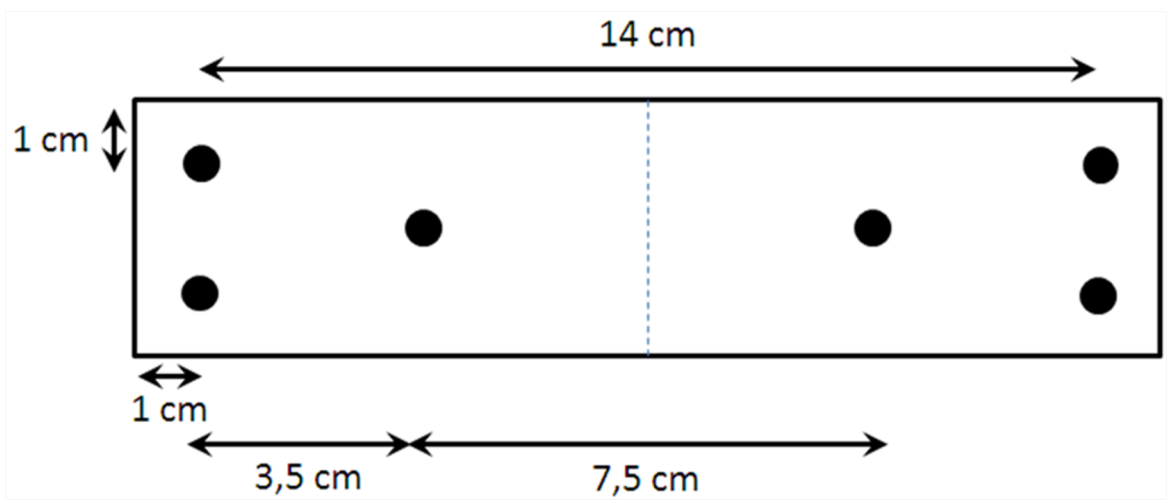

150 Figure 1. Location of the electrodes in the specimens

152 The electrical properties of the samples were characterized with an Agilent HP 4192A

153 impedance analyser, using an instrumentation amplifier as a front-end to allow 4-probe

154 measurements [32], with an effective voltage of $1 \mathrm{~V}$ AC to avoid polarisation effects in the

155 electrodes $[31,32]$. The measurements were conducted in the frequency scanning range of 10

$156 \mathrm{~Hz}$ to $1 \mathrm{MHz}$ providing electrical impedance $(Z$, in $\Omega)$ and phase ( $\phi$, in degrees). The 
157 electrical impedance is described by equation 2 and is composed of a real part (resistance, $R$ )

158 and an imaginary part (reactance, $X$ ); $R$ and $X$ are given by Equation 3 and 4:

$$
\begin{gathered}
Z=R+j \cdot X \\
R=Z \cdot \cos \left(\frac{\phi \cdot \pi}{180}\right) \\
X=Z \cdot \sin \left(\frac{\phi \cdot \pi}{180}\right)
\end{gathered}
$$

162 The electrical resistivity $(\rho$, in $\Omega \cdot \mathrm{m})$ was calculated from the impedance data using Eq. 5, where,

$163 S$ is the effective transverse section $\left(0.0016 \mathrm{~m}^{2}\right.$ in our study), and $l$ is the measurement length

164 (0.07 $\mathrm{m}$ in our study). All the samples were allowed to reach a hygrothermic equilibrium by

165 storing them under laboratory conditions for 15 days after finishing the curing period. Lastly,

166 the electrical conductivity $(\sigma, \mathrm{S} / \mathrm{m})$ of the samples was easily calculated as the inverse of the

167 resistivity, using Eq. 6. The electrical conductivity values are expressed as the mean of values

168 determined for three different specimens.

$$
\rho=R \frac{S}{l}
$$

$$
\sigma=\frac{1}{\rho}
$$

171 Piezo-resistivity tests were performed on $40 \times 40 \times 160 \mathrm{~mm}$ specimens to evaluate the

172 characteristics of the different conductive concrete samples. Samples were loaded both under

173 flexural and compression conditions. Electric current was passed through the samples using an

174 external DC current source (Keithley Model 6020) to monitor the resistivity variation during

175 the mechanical tests, by fixing the output current to $3 \mathrm{~V}$. Piezo-resistivity measurements were

176 performed on one specimen of each dosage. 


\section{RESULTS}

\section{$179 \quad 3.1 \quad$ Physical and mechanical properties}

180 The influence of the rCF type and content, as well as the mixing method on the slump flow is

181 depicted in Figure 1a. The rCF fibres supplied as fibrillated sheets (CT12) exhibited a larger 182 slump flow compared to that of monofilament $\mathrm{rCF}(\mathrm{C} 10 / 30)$ at all fibre dosages. A larger slump 183 flow is usually related with better dispersion of the $\mathrm{rCF}$ in the cementitious matrix and is 184 strongly affected by the geometrical parameters of the fibre (fibre factor, $F$ ).

185

186
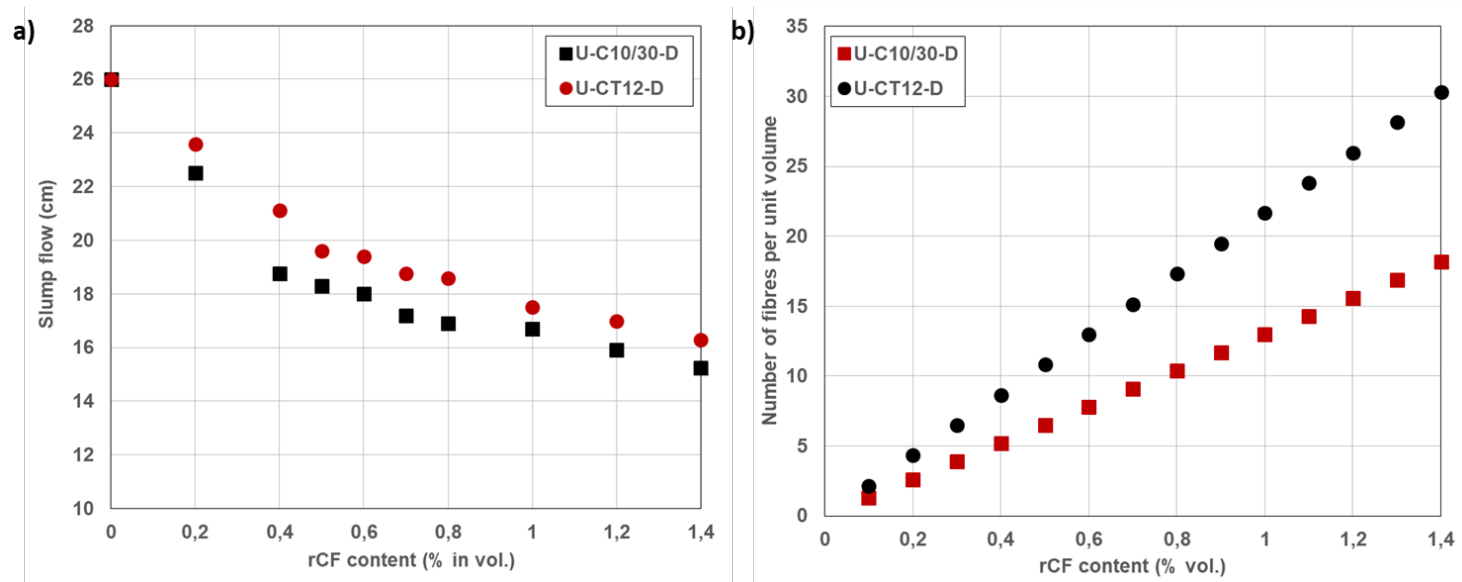

187 Figure 2. Variation of: (a) slump flow with the content of rCF for the different mixes, and (b)

$188 N$ per unit volume with the rCF content for C10/30 and CT12 fibres

190 Considering the differences in the properties of the two types of rCF shown in Table 2, larger

191 differences would be expected in the slump flow of concrete with C10/30 and CT12 samples.

192 However, the fibre dispersion in cementitious materials is affected not only by the fibre factor

193 but also by the number of fibres per unit volume, $N$. This parameter can be calculated according 194 to Eq. 7,

$$
N=\frac{V_{f}}{\pi \cdot\left(d_{f} / 2\right)^{2} \cdot L_{f}}
$$


where, $V_{f}$ is the volume fraction, $d_{f}$ is the diameter (in $\mathrm{mm}$ ), and $L_{f}$ is the length of carbon fibres

197 (in $\mathrm{mm}$ ). Figure $1 \mathrm{~b}$ shows the variation of $N$ with the $\mathrm{rCF}$ content for concrete samples containing $\mathrm{C} 10 / 30$ and $\mathrm{CT} 12$. For low rCF contents, the number of fibres per unit volume is very similar for both samples. As the rCF content increases, the difference between the $N$ values of C10/30 and CT12 samples increases. Thus, the results of slum flow reflect this relationship

201 between the geometrical factor of the fibres and the number of fibres per unit volume.

The mechanical properties of the specimens shown in Figure 3 also reflect the relationship between the geometrical factor of the fibres and the number of fibres per unit volume.

Considering the slump test results shown in Figure 2, a larger mechanical response of CT12 samples is expected. However, an inverse trend is observed with the C10/30 specimens exhibiting a larger mechanical response both under compressive and flexural conditions. This result might be explained again in view of the number of fibres per unit volume $(N)$. More carbon fibres in the bulk matrix can result in better mechanical performance up to a certain rCF content given by the fibre factor. Once this value is reached, a further increase in the carbon

211 fibre content might have a weakening effect owing to the presence of air voids and low 212 dispersion of the carbon fibres. As shown in Figure 3a, C10/30 and CT12 samples exhibit 213 almost similar compressive strengths at a low rCF content, because the number of fibres per 214 unit volume is very similar. As the rCF content increases, the difference between the $N$ value 215 of C10/30 and CT12 increases, and thus more defects (air voids and bundles of carbon fibres) 216 might be present in the cementitious matrix. 

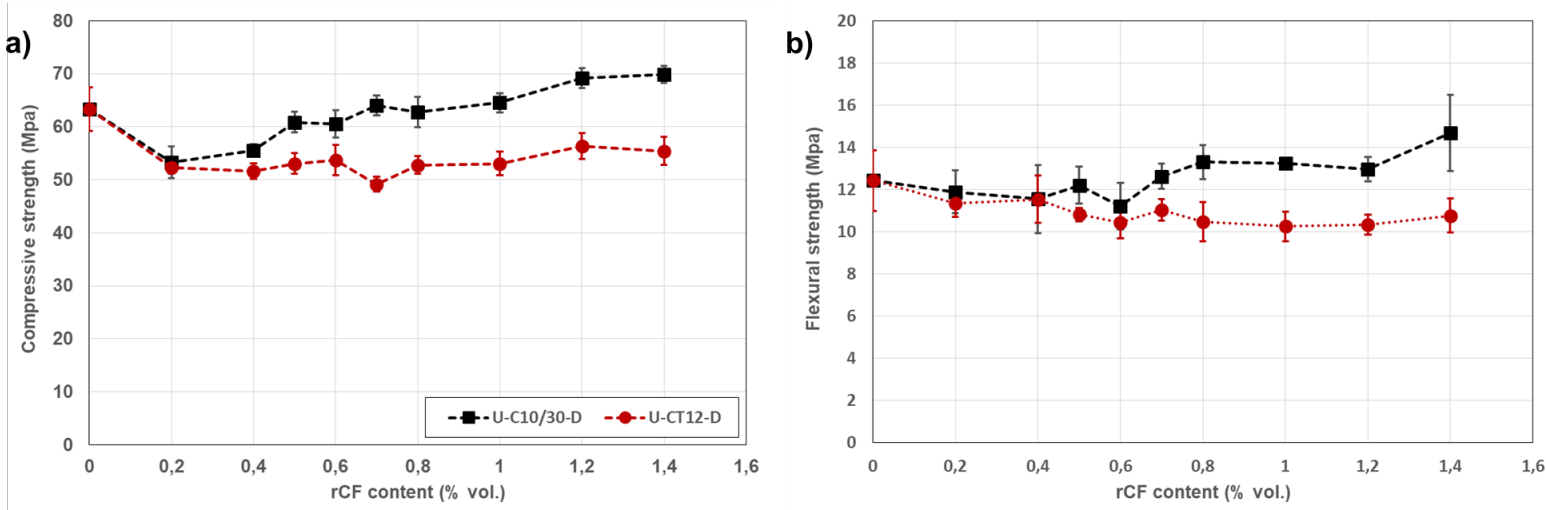

Figure 3. Variation of the a) compressive and b) flexural strengths with the fibre content for

220 different concrete mixes.

\subsection{Electrical conductivity}

223 The electrical characteristics of carbon fibre-reinforced cementitious composites are strongly

224 influenced by the applied frequency in AC measurements. Figure 4 shows the Bode diagrams

225 of a reference sample and a sample containing rCF. The reference sample behaves like an insulator with almost no variation in the impedance with the frequency. The incorporation of the $\mathrm{rCF}$ modifies the electrical behaviour of the samples, and the impedance reduces as the frequency of the applied current is increased. As stated by several researchers, there is a cut-off frequency that permits bypassing of the cementitious matrix that surrounds the fibres in carbon

230 fibre-reinforced materials [35], referred to as cusp frequency. This cut-off frequency is also 231 displayed when $\mathrm{rCF}$ is used [28], and the values are 100 and $190 \mathrm{kHz}$, respectively, for $\mathrm{C} 10 / 30$ 232 and CT12 samples. The electrical resistivities were determined at two different frequency 233 values: $50 \mathrm{~Hz}$ and $190 \mathrm{kHz}$. The first value coincides with the standard frequency for AC, and 234 the second was selected to perform the measurements above the capacitance threshold $\left(C_{t}\right)$ 235 value, and thus bypass the cementitious matrix that surrounds the $\mathrm{rCF}[26,33]$. 


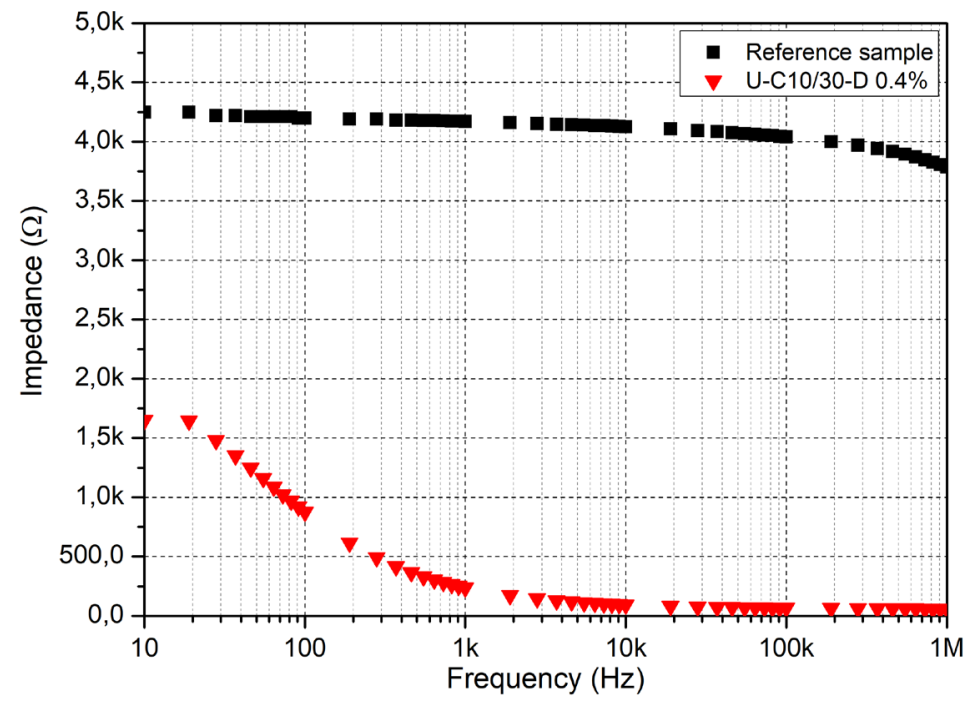

238 Figure 4. Bode diagrams for a reference concrete sample and an rCF-reinforced sample

The variation of the electrical conductivity with the fibre content for specimens with $\mathrm{C} 10 / 30$ and CT12 is shown in Figure 5, where the y axis presents different limits to accommodate the

242 different limits of both $\sigma_{50 \mathrm{~Hz}}$ and $\sigma_{190 \mathrm{kHz}}$. For low frequencies (see Figure 5a), specimens with 243 C10/30 exhibit larger electrical conductivity and CT12 specimens present electrical conductivities that are quite similar to that of the reference sample without rCF. Furthermore, the electrical conductivity of samples with $\mathrm{C} 10 / 30$ decreases for fibre contents larger than $0.6 \%$ vol. This electrical behaviour is related to the presence of carbon fibre bunches in the 247 cementitious matrix [25]. However, when the capacitance threshold is surpassed (Figure 5b), 248 the electrical behaviour is modified. Whereas the electrical conductivity of the reference sample 249 remains almost invariant (it varies from $0.0178 \mathrm{~S} / \mathrm{m}$ at $50 \mathrm{~Hz}$ to 0.0185 at $190 \mathrm{kHz}$ ), there is a 250 strong increase in the electrical conductivity of the specimens containing rCF. The samples with $251 \mathrm{C10} / 30$ fibres present a seven-fold increase in the electrical conductivity on average, while the 252 samples with CT12 fibres show a nineteen-fold increase on average. Although the number of 253 fibres per unit volume of CT12 samples is larger than that of C10/30 samples, the presence of 254 fibre bunches limits the electrical properties of the former. However, for frequencies above the 
capacitance threshold, the effect of the fibre bunches on the electrical conductivity is diminished 256 and the electrical conductivity of both C10/30 and CT12 samples becomes equal.
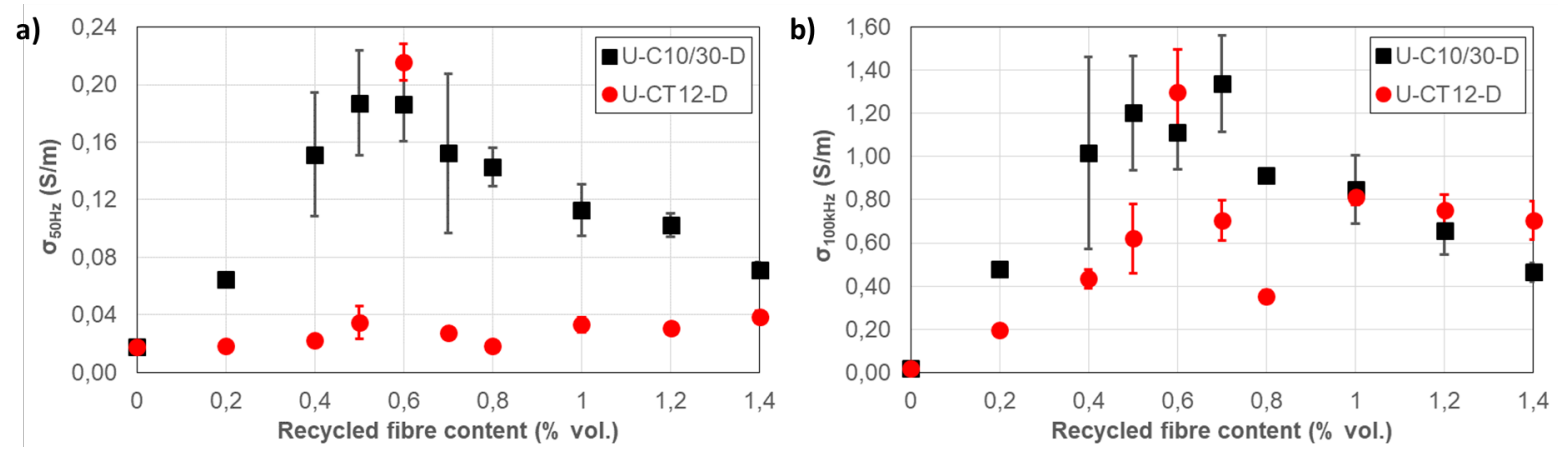

Figure 5. Variation of the electrical conductivity with the fibre content: a) at $50 \mathrm{~Hz}$, and b) at $190 \mathrm{kHz}$.

The electrical properties of carbon fibre-reinforced cementitious composites depend mostly on two different parameters: the dispersion of the fibre in the cementitious matrix and the waviness of the carbon fibres. The goodness of fibre dispersion in the cementitious matrix will determine the presence of fibre agglomerates (clusters). Furthermore, the characteristics of the carbon fibres usually utilised in cementitious composites may affect its waviness and thus its actual length. Both parameters will determine the presence of a continuous path of fibres and thus the electrical conductivity of the composite. García-Macías [36] studied both the effect of clustering and waviness on the electrical conductivity of CNT cementitious composites. The results shown in Figure 5 are consistent with the combined effect of clustering and waviness.

\subsection{Piezo-resistive response of specimens under laboratory conditions}

273 Figure 6 shows the load-voltage curves obtained for different concrete specimens made with 274 different contents of $\mathrm{C} 10 / 30 \mathrm{rCF}$ during compression tests. First, it is noticeable that the reference specimen without $\mathrm{rCF}$ also shows a piezo-resistive effect. A small variation in the 
voltage curve can be observed repeatedly, coinciding with the maximum and minimum values

277 of the applied load. The piezo-resistive responses were also observed using DC, and thus ionic effects can be observed in the voltage curve represented by the voltage drop from the start to

279 the end of the test.

280

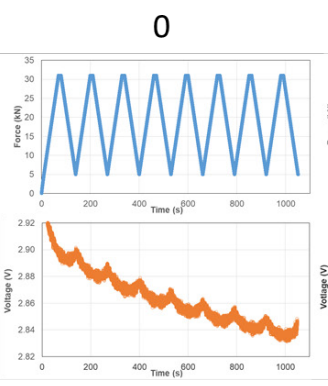

0.7

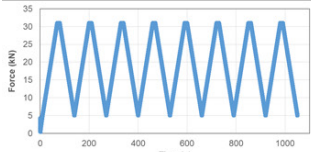

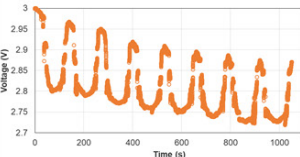

0.2

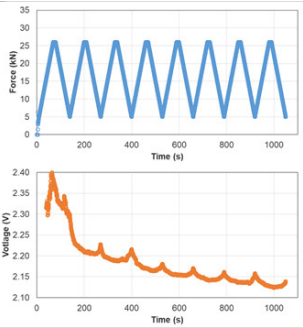

0.8
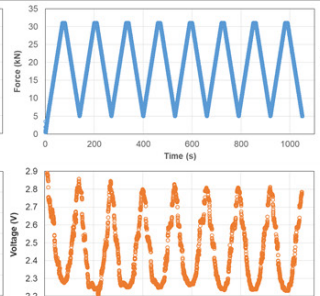

0.4
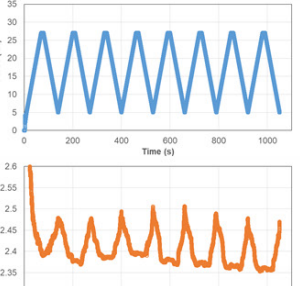

1.0
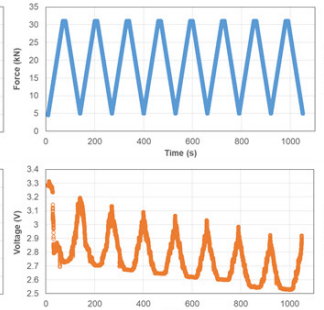

0.5
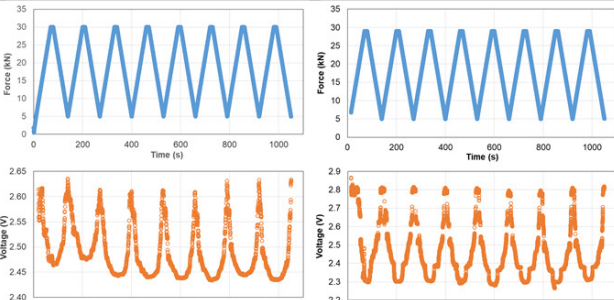

1.2
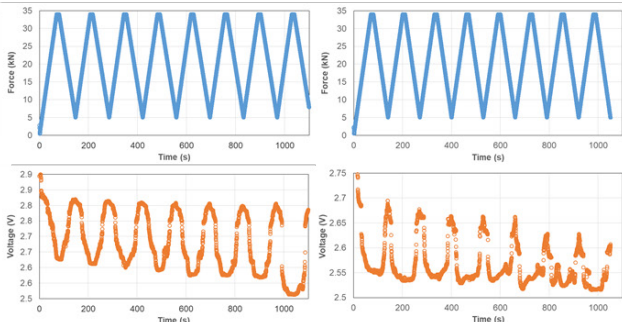

Figure 6. Load-voltage curves for the concrete specimens prepared with $\mathrm{C} 10 / 30 \mathrm{rCF}$ during the

compression tests. The numbers above the curves indicate the $\mathrm{rCF}$ content of the concrete

specimens.

The introduction of the rCF has a remarkable effect on the voltage curve; it increases the amplitude of the voltage variation. The amplitude of the voltage variation depends on the $\mathrm{rCF}$ content and increases up to a fibre content of $0.8 \%$. However, the introduction of rCF also affects the stability of the voltage curve and for fibre contents above $0.2 \%$, the initial and final voltage is almost the same for different specimens. No evidences of the piezo-resistive effect were observed upon analysing the load-voltage curves obtained from flexural tests (see Figure 7). 
0
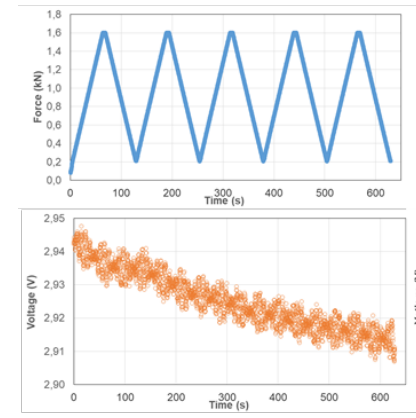

0.2
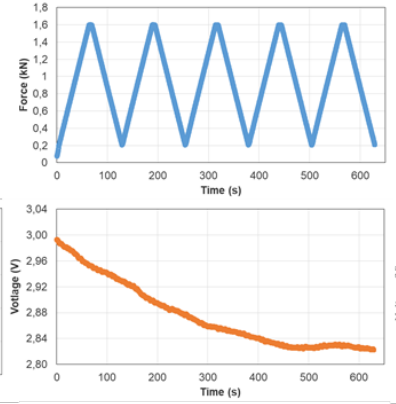

0.6
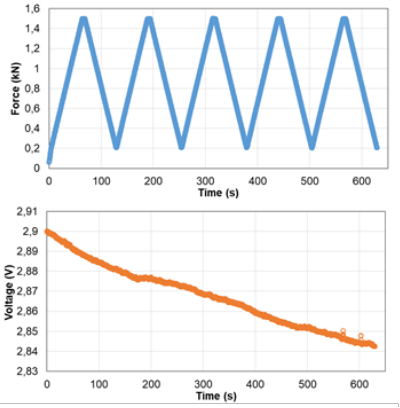

1.2
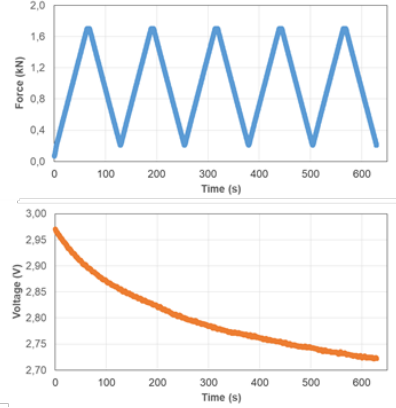

Figure 7. Load-voltage curves for the concrete specimens containing $\mathrm{C} 10 / 30 \mathrm{rCF}$ during the compression tests. The numbers above the curves indicate the rCF content of the concrete specimens.

Similar load-voltage curves were obtained for the specimens containing CT12 fibres, indicating of it was found during the flexural tests. The load-voltage curves in Figure 8 present some distinctive features presenting more noise and more irregular patterns that those shown in Figure 6. The different data obtained from the load-voltage curves during the compression tests are collected in Table 3.
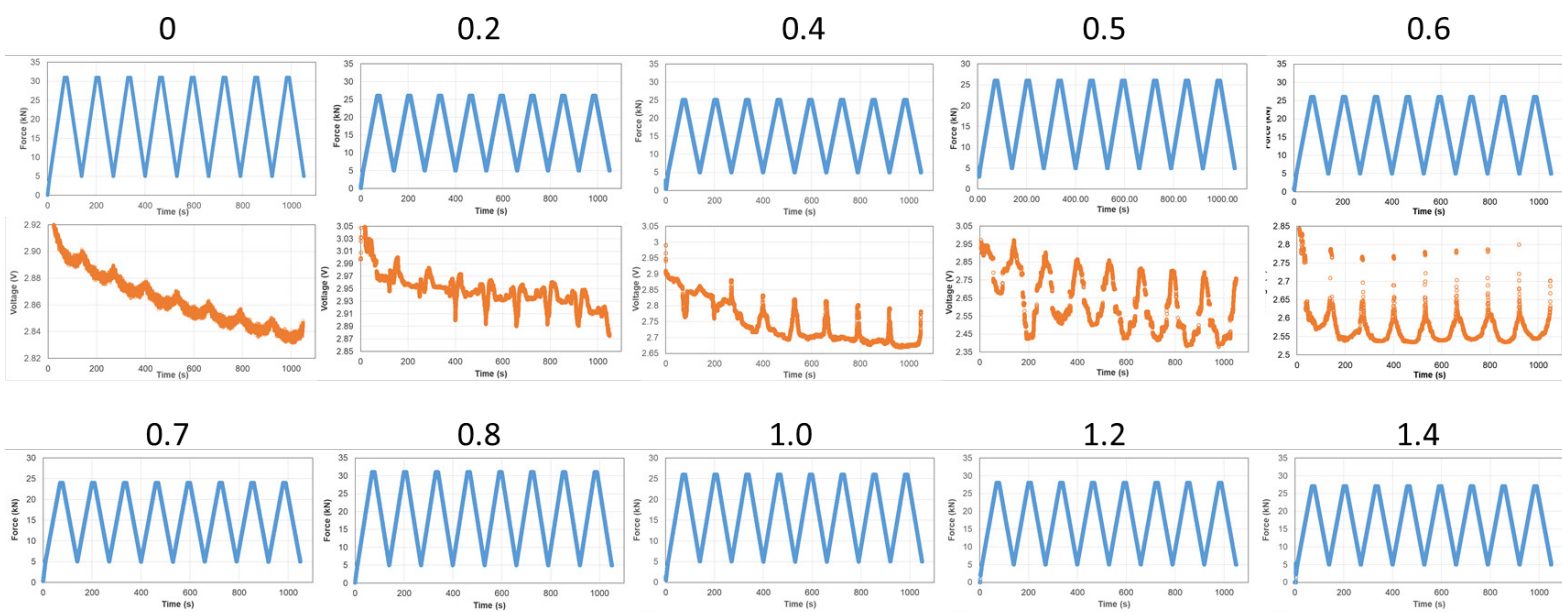

0.8

1.0

1.2

1.4
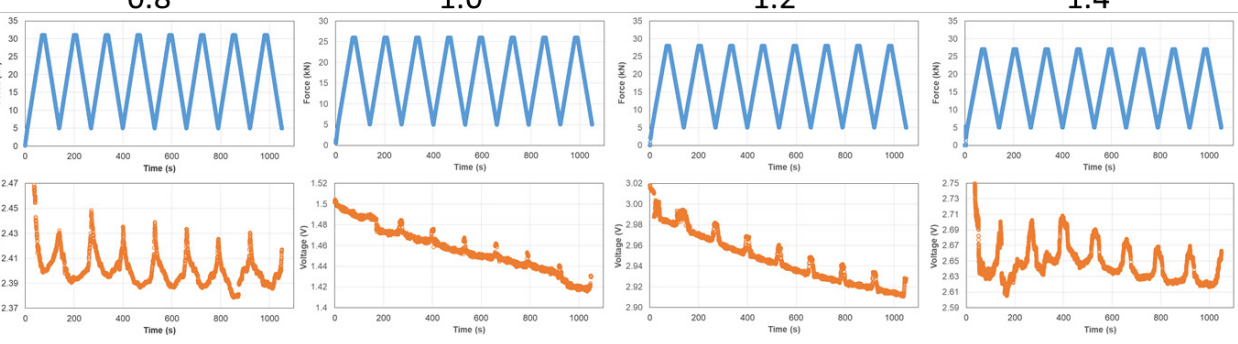
Figure 8. Load-voltage curves for the concrete specimens containing CT12 rCF during the compression tests.

Table 3. Parameters obtained from the load-voltage curves of concrete specimens with C10/30

311 and CT12 during the compression tests

\begin{tabular}{|c|c|c|c|c|}
\hline \multirow{2}{*}{$\begin{array}{c}\text { rCF } \\
\text { Content } \\
(\%)\end{array}$} & $\begin{array}{c}|c| \\
\text { C10/30 }\end{array}$ & \multicolumn{2}{c|}{ CT12 } \\
\cline { 2 - 5 }$(\mathbf{V})$ & $\begin{array}{c}\text { Voltage drop } \\
(\mathbf{V} \text { peak-peak }\end{array}$ & $\begin{array}{c}\text { Voltage drop } \\
\text { (V) }\end{array}$ & $\begin{array}{c}\Delta \mathbf{V}_{\text {peak-peak }} \\
(\mathbf{V})\end{array}$ \\
\hline 0 & -0.09 & 0.005 & -0.09 & 0.005 \\
\hline 0.2 & -0.89 & 0.02 & -0.20 & 0.04 \\
\hline 0.4 & -0.66 & 0.11 & -0.21 & 0.10 \\
\hline 0.5 & -0.35 & 0.38 & -0.22 & 0.17 \\
\hline 0.6 & -0.06 & 0.50 & -0.30 & 0.24 \\
\hline 0.7 & -0.13 & 0.15 & -0.20 & 0.27 \\
\hline 0.8 & -0.32 & 0.57 & -0.16 & 0.04 \\
\hline 1 & -0.37 & 0.41 & -0.07 & 0.009 \\
\hline 1.2 & -0.09 & 0.21 & -0.09 & 0.01 \\
\hline 1.4 & -0.16 & 0.12 & -0.05 & 0.05 \\
\hline
\end{tabular}

313 One of the parameters affected by the type of rCF used is the voltage drop measured during the

314 piezo-resistive tests, as shown in Figure 9. The voltage drop is related to the presence of the

315 polarisation phenomenon because of the movement of electrical charges during the test. The

316 polarisation phenomenon usually appears in cementitious materials when they are subjected to

317 an electrical field. Wen et al. have already shown that electrical polarisation diminishes when 318 carbon fibres are incorporated into cementitious matrices [37]. Samples incorporated with

$319 \mathrm{C} 10 / 30$ fibres present very large voltage drops for low fibre contents, and the voltage drop

320 diminishes with an increase in the rCF content. The voltage drop stabilises at approximately

$321-0.1$ to $0.2 \mathrm{~V}$. A further increase in the voltage drop in C10/30 samples may be related to the 322 presence of fibre bunches [28]. Samples incorporated with CT12 fibres present a voltage drop 
323 that almost shows no variation with the rCF content. For rCF contents below the percolation

324 threshold value ( $\sim 0.6 \%$ vol.), the voltage drop of CT12 specimens is lower than that of C10/30 325 samples.

326

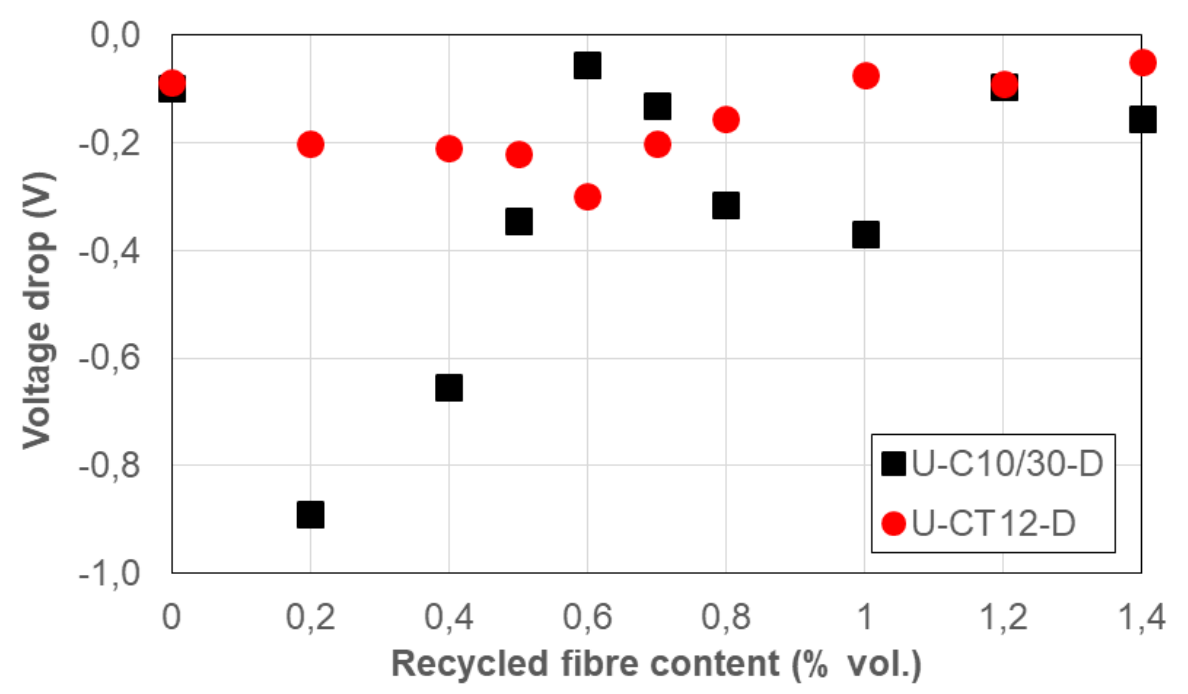

328 Figure 9. Voltage drop measured during the piezo-resistive tests.

330 The second parameter influenced by the type and content of $\mathrm{rCF}$ is the amplitude of the voltage

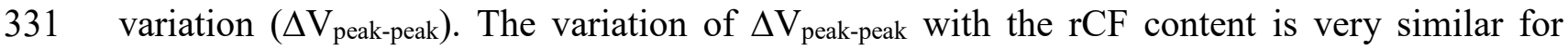
332 concrete samples with both rCF types, C10/30 and CT12, as shown in Figure 10, where three 333 different zones can be identified. In zone I, for low rCF contents (below $0.2 \%$ vol.), the $\Delta \mathrm{V}_{\text {peak- }}$ 334 peak values are very similar to that observed for the reference sample without rCF. Further 335 increase in the rCF content results in a linear increase in $\Delta \mathrm{V}_{\text {peak-peak }}$ up to the percolation 336 threshold value. The slope of the linear variation in zone II is different for C10/30 and CT12 337 fibres, with the corresponding slopes being 1.02 and 0.49 , respectively. 


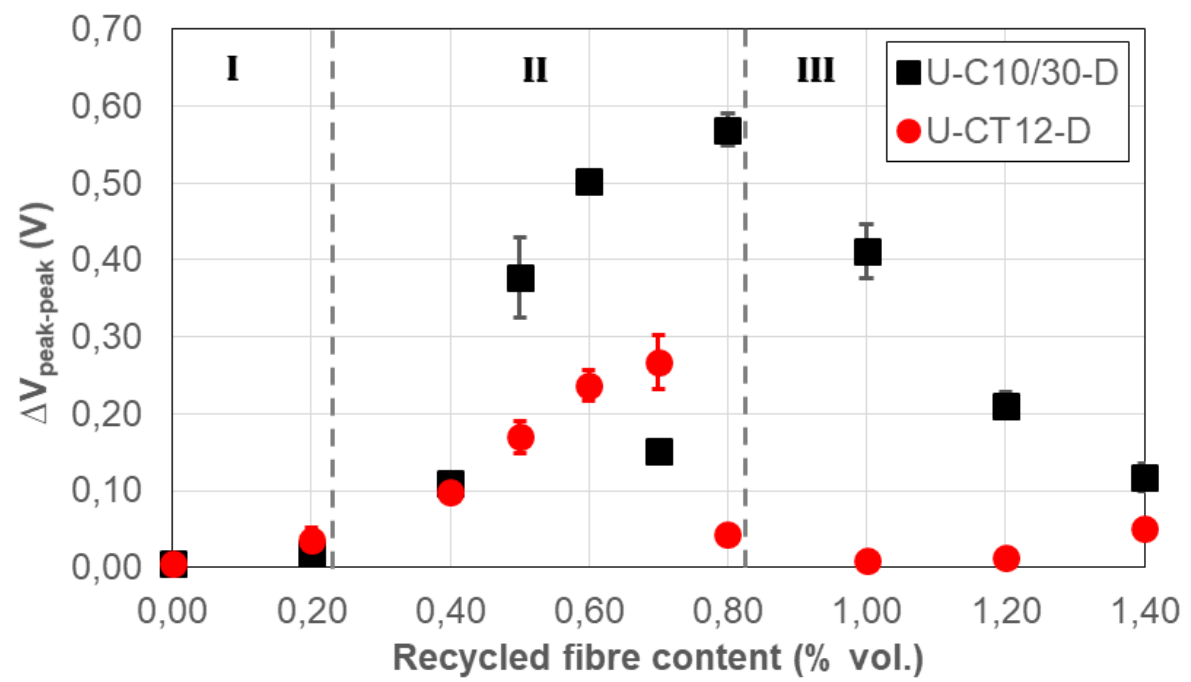

340 Figure 10 . Variation of $\Delta \mathrm{V}_{\text {peak-peak }}$ with the $\mathrm{rCF}$ content.

342 The observed behaviour can be explained considering the number of fibres per unit volume, $N$.

343 For rCF contents below $0.4 \%$, the differences in the numbers of fibres per unit volume of CT12

344 and C10/30 fibres are small, and thus low differences in is expected in the fibre dispersion.

345 However, as the rCF content increases, so does the difference in $N$. Lastly, in zone III, $\Delta \mathrm{V}_{\text {peak- }}$

346 peak diminishes with the fibre content because of the formation of fibre bunches in the

347 cementitious matrix, although the variation is clearly influenced by the fibre type. The samples

348 incorporated with $\mathrm{CT} 12$ fibre display a more drastic reduction in $\Delta \mathrm{V}_{\text {peak-peak }}$ for $\mathrm{rCF}$ contents

349 above the percolation threshold. Thus, the number of fibres per unit volume seems to play a

350 specific role in the conductivity of the concrete, and thus on the observed piezo-resistive 351 phenomenon.

353 However, some differences are observed when $\Delta \mathrm{V}_{\text {peak-peak }}$ is analysed considering the

354 conductivity of the samples (see Figure 11 ). Considering the hypothesis presented, $\Delta \mathrm{V}_{\text {peak-peak }}$ 355 could be expected to increase with the conductivity of the specimens up to a maximum value 356 related to the percolation threshold. The samples incorporated with $\mathrm{C} 10 / 30$ fibres agree with 357 this hypothesis at both $50 \mathrm{~Hz}$ and $190 \mathrm{kHz}$, with some outlier values (clearly identified in 
358 Figure 11 by shaded areas), which will be analysed further. However, samples incorporated 359 with CT12 fibres do not agree with this behaviour when analysed at $50 \mathrm{~Hz}$, but they agree 360 when the values of $\Delta \mathrm{V}_{\text {peak-peak }}$ are compared for $\sigma_{190 \mathrm{kHz}}$, with some outlier values.
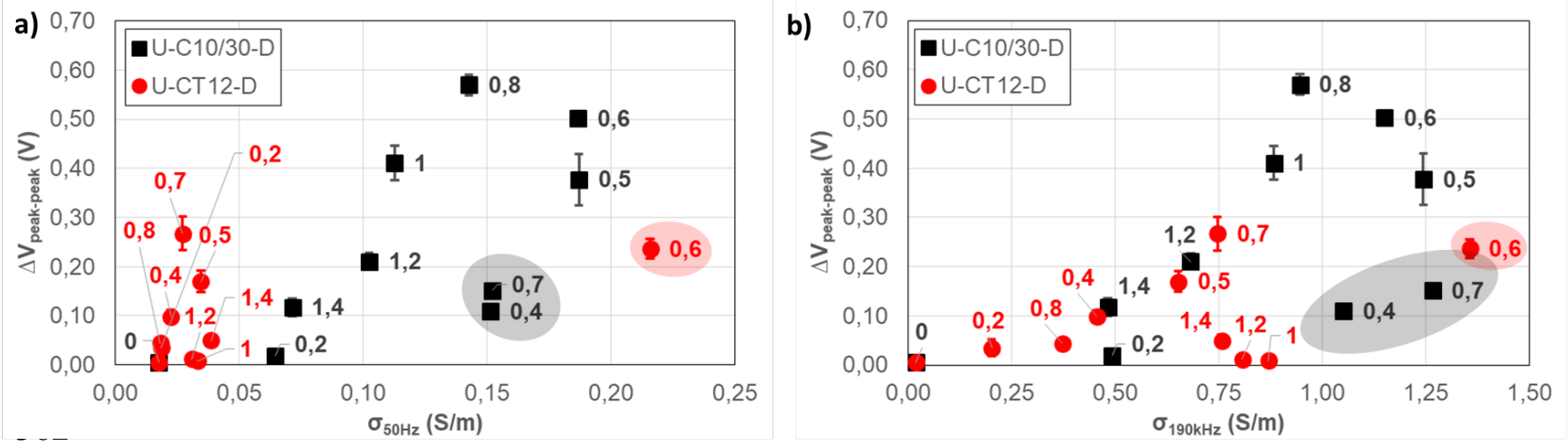

363 Figure 11. Variation of $\Delta \mathrm{V}_{\text {peak-peak }}$ with the conductivity for each rCF type: a) $\sigma_{50 \mathrm{~Hz}}$, and b)

$364 \sigma_{190 \mathrm{kHz}}$ (outliers identified by shaded areas).

366 The two values identified as outliers in the $\Delta \mathrm{V}_{\text {peak-peak }}$ vs $\sigma$ curve of the $\mathrm{C} 10 / 30$ samples were

367 also outliers in the $\Delta \mathrm{V}_{\text {peak-peak }}-V_{\mathrm{f}}$ curve and correspond respectively to the values immediately

368 below and above the percolation threshold (0.4 and $0.7 \%$ vol.) Similarly, the outlier in the

$369 \Delta \mathrm{V}_{\text {peak-peak }}-\sigma$ curve of the $\mathrm{C} 10 / 30$ sample corresponds to the $\mathrm{rCF}$ content at the percolation

370 threshold $(0.6 \%$ vol. $)$. However, the trends observed in the $\Delta \mathrm{V}_{\text {peak-peak }}-\sigma$ (Figure 11$)$ curves do

371 not correlate completely with the $\sigma-V_{\mathrm{f}}$ curves (Figure 5).

\section{DISCUSSION}

374 Several researchers have proposed models to account for the piezo-resistive responses of 375 conductive cementitious materials. The first studies on this topic were presented by Sun et al. 376 [38] and Wen \& Chung [5]. More recently, García-Macías et al. [36] presented a very detailed 377 review on the available models and proposed a new three-dimensional mixed micromechanics378 FEM modelling of piezo-resistive CNT smart concrete. Sun et al. [38] described the observation 
of piezo-resistive effects in plain cementitious materials and explained it in terms of a solid-

380 liquid interface double-layer model. In this situation, when a compressive force is applied, the 381 ions in the double-layer are transported to the cement pore solution because of the interface 382 shear stress. Thus, charges accumulate and a streaming potential difference arises. The load383 voltage curve of the reference samples (Figure 6) presents two different phenomena during 384 loading and unloading. During the loading of the sample, the voltage decreases because of a 385 leakage of charges through the conductive paths of the cementitious matrix and the flow of the cement pore solution. During unloading, a part of the solution refills the vacated pores and the voltage is increased. When the rCFs are incorporated into the cementitious matrix, the mechanism is mostly similar because of the cementitious paste that coats the carbon fibres. Two adjacent carbon fibres will always be surrounded by cementitious paste, but the thickness of this interface reduces as the $\mathrm{rCF}$ content is increased.

Thus, the incorporation of $\mathrm{rCF}$ does not alter the main mechanism of piezo-resistivity but amplifies the effect by increasing the signal-to-noise ratio. The signal-to-noise ratio, $S N R$, (in $\mathrm{dB})$ is estimated by Eq. 8 , as the ratio of the value of a given parameter $\left(\sigma_{50 \mathrm{~Hz}}, \sigma_{190 \mathrm{kHz}}\right.$, or $\Delta \mathrm{V}_{\text {peak- }}$ peak) for a concrete sample with a given $\mathrm{rCF}$ content to that of the same parameter for the plain concrete sample:

$$
S N R=10 \cdot \log \left(P_{\text {signal }} / P_{\text {noise }}\right)
$$

398 The influence of the rCF content on the SNR is presented in Figure 12, where two different 399 behaviours can be identified. First, the SNR of $\sigma_{50 \mathrm{~Hz}}$ and $\sigma_{190 \mathrm{kHz}}$ presents a slight increase for 400 rCF contents below the percolation threshold and stabilizes for further increases in the rCF. The 401 average SNR values of $\sigma_{50 \mathrm{~Hz}}$ and $\sigma_{190 \mathrm{kHz}}$ differ significantly for a given fibre type, as shown in Table 4. Moreover, the average SNR values $\sigma_{50 \mathrm{~Hz}}$ also differ significantly for C10/30 and CT12 403 fibres, however, on the contrary, the SNR values of $\sigma_{190 \mathrm{kHz}}$ are very similar. The conductivity 
404 measurements for frequencies below the capacitance threshold $(50 \mathrm{~Hz})$ are controlled by the 405 fibre-matrix interface, and thus by the dispersion of the carbon fibres.

406
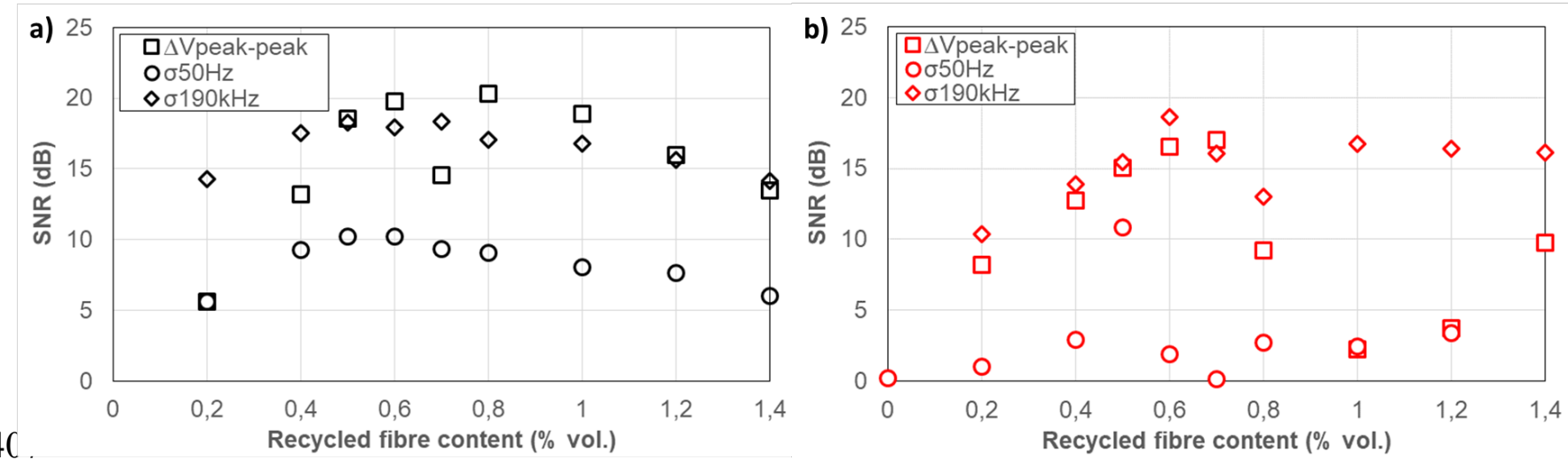

408 Figure 12. Variation of the SNR of $\sigma_{50 \mathrm{~Hz}}, \sigma_{190 \mathrm{kHz}}$, and $\Delta \mathrm{V}_{\text {peak-peak }}$ for a) U-C10/30-D

409 specimens, and b) U-CT12-D specimens

411 As discussed previously, the specimens incorporated with CT12 fibres in our study are more

412 likely to present fibre bunches than the ones incorporated with $\mathrm{C} 10 / 30$ fibres, because of the

413 larger number of fibres per unit volume of the former. Therefore, the SNR of $\sigma_{50 \mathrm{~Hz}}$ reflects the

414 influence of the fibre-matrix interface. However, for frequency values above the capacitance

415 threshold $(190 \mathrm{kHz})$, the conductivity values are mainly influenced by the electronic conduction

416 and the effects of the fibre-matrix interface are reduced. Thus, the SNR of $\sigma_{190 \mathrm{kHz}}$ is very similar

417 for both fibre types. The variation in the $\mathrm{SNR}$ of $\Delta \mathrm{V}_{\text {peak-peak }}$ with the $\mathrm{rCF}$ content presents a

418 mixed behaviour between $\sigma_{50 \mathrm{~Hz}}$ and $\sigma_{190 \mathrm{kHz}}$. For values below the percolation threshold, the SNR

419 values of $\Delta \mathrm{V}_{\text {peak-peak }}$ are similar to those of $\sigma_{50 \mathrm{~Hz}}$. This behaviour is observed in the samples

420 incorporated with both $\mathrm{C} 10 / 30$ and $\mathrm{CT} 12$ fibres. For $\mathrm{rCF}$ contents above the percolation

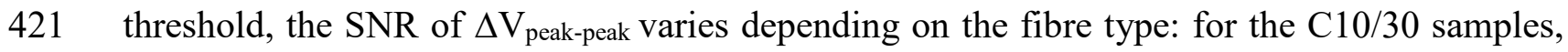

422 the SNR almost shows no variation with increasing rCF content, whereas for the CT12

423 specimens, there is a strong decrease in the SNR followed by an increase for larger $\mathrm{rCF}$ 
contents. This mixed behaviour may be attributed to a mixed control of the piezo-resistive 425 phenomena in these samples. For rCF contents below the percolation threshold, the main controlling factor is the fibre-matrix interface, whereas for larger rCF contents, the controlling factor varies between the electronic transfer mechanism and the fibre-matrix interface, depending on the characteristics of the fibre dispersion in the cementitious matrix.

Table 4. Average values of SNR for different parameters and rCF types

\begin{tabular}{|c|c|c|}
\hline \multirow{2}{*}{ SNR (dB) } & \multicolumn{2}{|c|}{ Fibre type } \\
\cline { 2 - 3 } & $\mathbf{C 1 0} / \mathbf{3 0}$ & $\mathbf{C T 1 2}$ \\
\hline$\sigma_{50 \mathrm{~Hz}}$ & 8.4 & 2.8 \\
\hline$\sigma_{190 \mathrm{kHz}}$ & 16.7 & 15.2 \\
\hline$\Delta \mathrm{V}_{\text {peak-peak }}$ & 15.6 & 10.5 \\
\hline
\end{tabular}

432 The observed behaviour is in agreement with previous observations by Sun et al. [39], which were more recently confirmed by Baeza et al. [40], who proposed a constitutive model for the electrical behaviour of carbon fibre-reinforced composites. This model includes four possible conductive mechanisms: 1) ionic conductivity, 2) conductivity due to electronically conductive fibres in the cement matrix and conductive holes, 3) conductivity due to electronically 437 conductive paths between the fibres and the continuous conductive holes, and 4) conductivity 438 due to electronically conductive fibres passing through the conductive network past the conductive hole. For a sample with low carbon fibre content, the main conductive mechanisms

440 are 1) and 2). As the fibre content increases, electrical conduction occurs mainly via 441 mechanisms (2) and (3). When the fibre content is increased above the percolation threshold, 442 mechanism 4) becomes the main pathway. Therefore, the piezo-resistive phenomena shown in 443 Figure 6 and Figure 8 reflect both the influence of the fibre-matrix interface and the electronic 444 transfer mechanism. For low rCF contents, the thickness of the fibre-matrix interface is large 445 and so is the distance between the carbon fibres. Thus, for low rCF contents the fibre-matrix 
446 interface in the cementitious matrix will control the piezo-resistive response of the composite.

447 As the rCF content is increased up to the percolation threshold, the thickness of the cementitious 448 matrix surrounding the fibres reduces, and thus the electronic transfer mechanism becomes

449 dominant in the piezo-resistive phenomenon. For rCF contents above the percolation threshold, 450 the presence of fibre bunches and the effect of the fibre waviness will determine the observed 451 behaviour, and thus the fibre-matrix interface increasingly influence the piezo-resistive 452 behaviour.

\section{CONCLUSIONS}

455 The piezo-resistive phenomenon observed in cementitious materials is inherent to their porous 456 structure and the enclosed aqueous solution. The piezo-resistive effect in these materials could 457 be increased by incorporating carbon fibres. In this article, we demonstrated that rCFs can also 458 be incorporated in cementitious composites to increase their piezo-resistive responses. 459 Furthermore, we showed that the main parameters that control the electrical behaviour of carbon 460 fibre-reinforced cementitious composites (fibre dispersion and fibre waviness) also determine 461 the piezo-resistive responses of our cement composites. For rCF contents below the percolation 462 threshold, the piezo-resistive response is mainly controlled by the thickness of the cementitious 463 paste surrounding the $\mathrm{rCF}$, and thus small piezo-resistive response was obtained. When the rCF 464 was increased, the electronic transfer mechanism started to control the electrical behaviour, and 465 thus the piezo-resistive response increased. However, for $\mathrm{rCF}$ contents above the percolation 466 threshold, the presence of fibre bunches and the waviness of the carbon fibres determine the 467 main parameter that controls the electrical behaviour: (i) the fibre-matrix interface and thus the 468 ionic conductivity or (ii) the electronic conduction. The results presented in this paper open new 469 possibilities for the development of smart cementitious materials that can be introduced into 470 civil engineering structures. The use of recycled carbon fibres and of fabrication procedures 
471 similar to those used by the civil engineering industry allow the development of cementitious

472 composites with properties that are equivalent to those of materials fabricated with expensive 473 carbonaceous materials or using sophisticated fabrication and dispersion protocols.

\section{Acknowledgements}

476 The authors acknowledge the financial support provided by the Spanish Ministry of Economy 477 and Competitiveness through the Torres Quevedo Program (postdoctoral fellowships, PTQ-1447807072 and PTQ-15-07562), as well as the support from the Catalan Government through the 479 Industrial Doctorate program, DI-2015-013. The authors also thank the company, Escofet 1886 480 for their collaboration and support throughout the entire project.

\section{References}

483 [1] A. Barrias, J. Casas, and S. Villalba, "A Review of Distributed Optical Fiber Sensors for Civil Engineering Applications," Sensors, vol. 16, no. 5, p. 748, May 2016.

[2] D. Zonta, H. Wu, M. Pozzi, P. Zanon, M. Ceriotti, L. Mottola, G. P. Picco, A. L. Murphy, S. Guna, and M. Corrà, "Wireless sensor networks for permanent health monitoring of historic buildings," Smart Struct. Syst., vol. 6, no. 5-6, pp. 595-618, Jul. 2010.

[3] H. Ceylan, "Use of smart sensor systems for health monitoring of the transportation infrastructure system," in 3rd International Conference on Transportation Infrastructure, 2014.

492 [4] P.-W. Chen and D. D. L. Chung, "Carbon fiber reinforced concrete for smart structures capable of non-destructive flaw detection," Smart Mater. Struct., vol. 2, no. 1, pp. 2230, 1993.

495 [5] S. Wen and D. D. L. Chung, "Model of piezoresistivity in carbon fiber cement," Cem. 
Concr. Res., vol. 36, no. 10, pp. 1879-1885, 2006.

497 [6] M. Taya, W. J. Kim, and K. Ono, "Piezoresistivity of a short fiber/elastomer matrix composite," Mech. Mater., vol. 28, no. 1-4, pp. 53-59, Jul. 1998.

499 [7] P. W. Chen and D. D. L. Chung, "Concrete as a new strain/stress sensor," Compos. Part B Eng., vol. 27, no. 1, pp. 11-23, 1996.

$501 \quad$ [8] Z. Q. Shi and D. D. L. Chung, "Carbon fiber-reinforced concrete for traffic monitoring 502 and weighing in motion," Cem. Concr. Res., vol. 29, no. 3, pp. 435-439, 1999.

[9] D. D. L. Chung, “Cement-matrix composites for smart structures," Smart Materials and Structures, vol. 9, no. 4. pp. 389-401, 2000.

[10] D. D. L. Chung, "Cement reinforced with short carbon fibers: A multifunctional material," Compos. Part B Eng., vol. 31, no. 6-7, pp. 511-526, 2000.

[11] F. J. Baeza, O. Galao, E. Zornoza, and P. Garcés, "Multifunctional cement composites 508 strain and damage sensors applied on reinforced concrete (RC) structural elements," Materials (Basel)., vol. 6, no. 3, pp. 841-855, Mar. 2013.

[12] F. J. Baeza, E. Zornoza, L. G. Andión, S. Ivorra, and P. Garcés, "Variables affecting strain sensing function in cementitious composites with carbon fibers," Comput. Concr., vol. 8, no. 2, pp. 229-241, Apr. 2011.

[13] Q. Liu, Q. Xu, Q. Yu, R. Gao, and T. Tong, "Experimental investigation on mechanical and piezoresistive properties of cementitious materials containing graphene and graphene oxide nanoplatelets," Constr. Build. Mater., vol. 127, pp. 565-576, 2016.

[14] O. Galao, F. Baeza, E. Zornoza, and P. Garcés, "Carbon Nanofiber Cement Sensors to Detect Strain and Damage of Concrete Specimens Under Compression,” Nanomaterials, vol. 7, no. 12, p. 413, 2017.

[15] M. S. Konsta-Gdoutos and C. A. Aza, "Self sensing carbon nanotube (CNT) and nanofiber (CNF) cementitious composites for real time damage assessment in smart 
structures," Cem. Concr. Compos., vol. 53, pp. 162-169, Oct. 2014.

522

523

524

525

526

527

528

529

530

531

532

533

534

535

536

537

538

539

540

541

542

543

544

545

[16] L. Coppola, A. Buoso, and F. Corazza, "Electrical Properties of Carbon Nanotubes Cement Composites for Monitoring Stress Conditions in Concrete Structures," Appl. Mech. Mater., vol. 82, pp. 118-123, Jul. 2011.

[17] B. Han, X. Yu, K. Zhang, E. Kwon, and J. Ou, "Sensing properties of CNT-filled cement-based stress sensors," J. Civ. Struct. Heal. Monit., vol. 1, no. 1-2, pp. 17-24, Jun. 2011.

[18] S. Dong, B. Han, J. Ou, Z. Li, L. Han, and X. Yu, "Electrically conductive behaviors and mechanisms of short-cut super-fine stainless wire reinforced reactive powder concrete," Cem. Concr. Compos., vol. 72, pp. 48-65, 2016.

[19] Y. Ding, Z. Han, Y. Zhang, and J. B. Aguiar, "Concrete with triphasic conductive materials for self-monitoring of cracking development subjected to flexure," Compos. Struct., vol. 138, pp. 184-191, 2016.

[20] Y. Ding, Y. Huang, Y. Zhang, S. Jalali, and J. B. Aguiar, "Self-monitoring of freezethaw damage using triphasic electric conductive concrete," Constr. Build. Mater., vol. 101, pp. 440-446, 2015.

[21] Y. Ding, Z. Chen, Z. Han, Y. Zhang, and F. Pacheco-Torgal, "Nano-carbon black and carbon fiber as conductive materials for the diagnosing of the damage of concrete beam," Constr. Build. Mater., vol. 43, pp. 233-241, 2013.

[22] K. J. Loh and J. Gonzalez, "Cementitious composites engineered with embedded carbon nanotube thin films for enhanced sensing performance," in Journal of Physics: Conference Series, 2015, vol. 628, no. 1, p. 12042.

[23] B. Han, S. Ding, and X. Yu, Intrinsic self-sensing concrete and structures: A review, vol. 59. Elsevier Ltd, 2015, pp. 110-128.

[24] B. Han, X. Yu, and E. Kwon, “A self-sensing carbon nanotube/cement composite for 
traffic monitoring," Nanotechnology, vol. 20, no. 44, p. 445501, 2009.

[25] B. Han, K. Zhang, T. Burnham, E. Kwon, and X. Yu, "Integration and road tests of a self-sensing CNT concrete pavement system for traffic detection," Smart Mater. Struct., vol. 22, no. 1, p. 015020, Jan. 2013.

[26] S. Pimenta and S. T. Pinho, "Recycling carbon fibre reinforced polymers for structural applications: Technology review and market outlook," Waste Manag., vol. 31, no. 2, pp. 378-392, Feb. 2011.

[27] S. J. Pickering, "Recycling technologies for thermoset composite materials - current status," Compos. Part A Appl. Sci. Manuf., vol. 37, pp. 1206-1215, 2006.

[28] G. Faneca, I. Segura, J. M. Torrents, and A. Aguado, “Development of conductive cementitious materials using recycled carbon fibres," Cem. Concr. Compos., vol. 92, pp. 135-144, 2018.

[29] R. Narayanan and I. Y. S. Darwish, "Use of Steel Fibers as Shear Reinforcement," Struct. J., vol. 84, no. 3, pp. 216-227, 1987.

[30] AENOR, “UNE-EN 196-1:2005 Methods of testing cement. Part I: Determination of strength." 2005.

[31] AENOR, "UNE-EN 1015-3:2000 Methods of test for mortar for masonry. Determination of consistence of fresh mortar (by flow table).” 2000.

[32] E. Gersing, "Measurement of electrical impedance in organs measuring equipment for research and clinical applications," Biomed. Tech., vol. 36, pp. 6-11, 1991.

[33] S. Wen and D. D. L. Chung, "The role of electronic and ionic conduction in the electrical conductivity of carbon fiber reinforced cement," Carbon N. Y., vol. 44, no. 11, pp. 2130-2138, 2006.

[34] S. Wen and D. D. L. Chung, "Double percolation in the electrical conduction in carbon fiber reinforced cement-based materials," Carbon N. Y., vol. 45, no. 2, pp. 263-267, 
572 [35] T. O. Mason, M. A. Campo, A. D. Hixson, and L. Y. Woo, "Impedance spectroscopy of fiber-reinforced cement composites," Cem. Concr. Compos., vol. 24, no. 5, pp. 457 $465,2002$.

[36] E. García-Macías, A. D. Alessandro, and R. Castro-triguero, "Micromechanics modeling of the electrical conductivity of carbon nanotube cement-matrix composites," Composite, vol. 108, pp. 451-469, 2017.

[37] S. Wen and D. D. L. Chung, "Electric polarization in carbon fiber-reinforced cement," Cem. Concr. Res., vol. 31, no. 1, pp. 141-147, 2001.

[38] M. Sun, Q. Liu, Z. Li, and Y. Hu, “A study of piezoelectric properties of carbon fiber reinforced concrete and plain cement paste during dynamic loading," Cem. Concr. Res., vol. 30, no. 10, pp. 1593-1595, Oct. 2000.

[39] M. Sun, Z. Li, Q. Mao, and D. Shen, "Study on the Hole Conduction Phenomenon in Carbon Fiber-Reinforced Concrete," Cem. Concr. Res., vol. 28, no. 4, pp. 549-554, Apr. 1998.

[40] F. J. Baeza, O. Galao, I. J. Vegas, M. Cano, and P. Garcés, "Influence of recycled slag aggregates on the conductivity and strain sensing capacity of carbon fiber reinforced cement mortars," Constr. Build. Mater., vol. 184, pp. 311-319, Sep. 2018. 